\title{
Evidence-Based Course Modification to Support Learner-Centered and Student-Driven Teaching in A Pandemic: Leveraging Digital and Physical Space for Accessible, Equitable, and Motivating Experiential Learning and Scientific Inquiry in A First-Year Biology Course
}

\author{
Lisa Robertson ${ }^{1,2,3}$, Elizabeth Porter ${ }^{1}$, M. Alex Smith ${ }^{1}$ \& Shoshanah Jacobs ${ }^{1,2}$ \\ ${ }^{1}$ Department of Integrative Biology, University of Guelph, Guelph, Canada \\ ${ }^{2}$ College of Biological Sciences Office of Educational Scholarship and Practice, University of Guelph, Guelph, \\ Canada \\ ${ }^{3}$ Current Department: Department of Biology, York University, Toronto, Canada \\ Correspondence: Lisa Robertson, Department of Biology, Faculty of Science, York University, Toronto, Ontario, M3J \\ 1P3, Canada.
}

Received: July 31, 2021

Accepted: September 10, 2021

Online Published: September 13, 2021

doi:10.5430/ijhe.v10n7p96

URL: https://doi.org/10.5430/ijhe.v10n7p96

\begin{abstract}
The COVID-19 pandemic posed, and continues to pose, many challenges to teaching and learning, most notably the need to pivot from traditional in-person course instruction and experiences to entirely virtual course delivery while maintaining course rigor and quality. Our guiding principle for course modification was the critical need for an equitable, accessible, engaging, and motivating learning experience for students that maintained the learning outcomes and objectives of the course in a fully virtual and digitized format. This paper illustrates the evidence-based approach that the instructional team of a first-year biology experiential learning course took in response to the need for instruction to occur in virtual space and time for the Fall 2020 (September to December 2020) semester.
\end{abstract}

Keywords: virtual learning, experiential learning, first year undergraduate, digitizing space, COVID-19, student support

\section{Introduction}

Postsecondary education instructors are challenged with maintaining program and course content relevance while using innovative teaching strategies and contemporary technologies to keep curriculum and teaching current and engaging. In large introductory first-year courses, supporting student learning can be a particular challenge because the learning environment often does little to support students in their transitions to postsecondary systems of education (Kerr, 2011). This can have significant effects on student mental health that, in combination with other institutionally internal and external factors (Cuseo, 2007), contributes to lower retention across the first to second year transition. Of particular importance to overcoming these challenges in first-year postsecondary education is the need to support students in learning the skills necessary to succeed (McIntosh \& Barden, 2019) while building a social network to allow them to develop a sense of belonging (O'Keeffe, 2013). These elements reduce attrition and contribute to student academic success.

The challenges associated with engaging and supporting first-year students in large introductory courses were magnified in March 2020 (Dietrich et al., 2020). By March 31, 2020 the impact of COVID-19 on education was evident, with schools in 170 countries closed to in-person instruction due to COVID-19 (United Nations Educational, Scientific and Cultural Organization [UNESCO], 2020). In the early stages of the COVID-19 pandemic, courses that relied heavily on in-person instruction were either cancelled or instructors were given only a few days to shift them online with little or no institutional support. The online transfer of experiential learning courses designed using active and hands-on learning pedagogical techniques was particularly challenging, and instructors at our institution were given the option to end the course early provided that at least $65 \%$ of the assessments had already been completed.

First year biology programs/majors at the University of Guelph include three core courses that students must take during the first two semesters of their program, each administered by one of three departments within the College of 
Biological Science that teach their topics of specialization through lectures, seminars, and/or laboratories. These three first-year courses are linked by common elements, including online skills workshops and an inter-course interdisciplinary project (Husband et al, 2015; Sigal \& Jacobs, 2019). One of these courses, Discovering Biodiversity (BIOL*1070), enrolls up to 1,800 students per academic year and is offered with 2 hours per week of in-class instructional support, and 1 hour per week of small group seminar instruction. During an offering, students engage in a variety of experiential and active learning activities, including fieldwork conducted in a local urban forest. Students work in mixed groups representing the three first-year courses on the interdisciplinary project, using course knowledge and skills developed through the online workshops to create a poster-style presentation that is presented in a simulated scientific conference experience. In an in-person offering, seminars scaffold scientific inquiry and the scientific method, and students use data collected during the urban forest fieldwork to complete the capstone activity (the Forest Fragmentation Assignment (FFA), which is designed to allow students to practice and demonstrate their skills in data collection, visualisation, and interpretation of findings.

This course was designed using several of the principles of Universal Design for Learning (UDL; e.g. creating cooperative learning groups with clear expectations (CAST, 2018)), and other evidence-based pedagogical principles (e.g. flipped classroom (i.e. McLaughlin et al., 2014), active learning (Prince, 2004), experiential learning (i.e. Kolb, 1984)). Self-directed learning and the theory of andragogy are at the core of adult learning theory (Merriam, 2001) and were also used when designing this course, including the establishment of a safe learning environment where students 1) feel comfortable expressing their opinions, 2) themselves, their knowledge, and experiences are perceived as valuable and a resource for learning, 3) act as partners in teaching and learning, and 4) are supported in devising strategies for success in learning and development of metacognitive skills (Knowles, 1977; Merriam, 2001).

In March 2020, the COVID-19 pandemic made it necessary to transfer courses from in-person instruction to virtual space, while ensuring that teaching and learning was equitable, accessible (e.g. Czerniewicz, Trotter, \& Haupt, 2019; Jacobs, Loring, \& Gillis, 2020; Thomsen et al., 2021), and engaging to support students experiencing declining mental health (Gazmararian, Weingart, Campbell, Cronin, \& Ashta, 2021). Many instructors were left using teaching tools that are not conducive to developing a sense of community, especially for those with little experience or training in using digital teaching tools (Hodges, Moore, Lockee, Trust, \& Bond, 2020). Thus, students enrolled in their first year at a postsecondary institution in the Fall 2020 semester (September to December 2020) were facing the challenges of the complex transition to postsecondary life, and adapting to virtual learning, in isolation. In response, the instructional team of BIOL*1070 used evidence-based approaches and theories to restructure and redesign the course for virtual delivery in Fall 2020, without modifications to existing learning outcomes (LOs). Changes to LOs require a lengthy bureaucratic process that was not possible within the short timeline given to make the necessary changes, therefore our LOs became our foundation. The overarching goals of the restructuring were to maintain our learner-centered approach to teaching by retaining the guiding principles of adult learning theory and self-directed learning, increase our support of students as they developed the skills necessary to transition successfully into postsecondary education, and facilitate the development of a sense of community in a virtual setting. We also focused on student support, especially in the realm of mental health and wellness, because declining student mental health, exacerbated by conditions created by the pandemic, is known to negatively affect student health and academic performance, and increase attrition (Wyatt, Oswalt, \& Ochoa, 2017). We accomplished our goals by employing a Pedagogy of Kindness (Gorny-Wegrzyn \& Perry, 2021; Hativa, Barak, \& Simhi, 2001; Rawle, 2021, as cited in Hariri, 2021; Serbati, Aquario, Re, Paccagnella, \& Felisatti, 2020), innovative digital technology, and an accessible citizen science bonus activity for students that, taken together, increased opportunities for student engagement, critical thinking, and application of knowledge.

\section{Educational Theories and Guiding Principles: Informing Teaching Practice}

High cognitive load, exacerbated during global events such as pandemics, reduces the possibility of learning. In these circumstances many students who do not drop out of courses cope by adopting surface learning approaches, resulting in a reliance on memorization for rote learning and the inability to apply content knowledge (de Jong, 2010). Course restructuring that acknowledges the effect of cognitive load, and that emphasizes longevity of learning, learner-centered approaches to teaching, and applicability of knowledge, can increase access to a course's structure, improve the learning experience of students, and may increase a student's motivation to learn (McCombs, 2015). In addition to using the principles of UDL, restructuring following a Constructive Alignment (Biggs, 1996) approach with an embedded Pedagogy of Kindness (Clegg \& Rowland, 2010) allows instructors to build a positive learning environment, ensuring that learning goals are aligned with both the LOs and the student learning context to facilitate better learning and personal outcomes. The reorganization of BIOL*1070 in response to the COVID-19 pandemic used an evidence-based approach, theories of higher education, and guiding principles to create a stimulating virtual student experience that did not overwhelm students with content but allowed students to flourish and develop a sense of 
community in the course. We used UDL and the evidence-based practices below due to their ease of application in the course redesign process, and because they are physical-space independent, allowing us to focus on the few elements that were place-specific, such as the urban forest on the grounds of the University of Guelph and other seminars that we digitized.

\subsection{Constructive Alignment and A Pedagogy of Kindness: A Path for Student Success}

Constructivism recognizes, justifies, and focuses on knowledge construction, the cognitive processes involved in this construction, and how preconceived notions or inherent biases may affect an individual student's learning process (Biggs, 1996). Practicing a constructivist approach to teaching involves using activities appropriate for the discipline, understanding the student point-of-view, and ensuring that learning activities support LOs. By applying this framework, an instructor is a facilitator of learning, and the student is the constructor of their knowledge. Students who construct their knowledge are better able to anchor this knowledge within their long-term memory (McCombs, 2015; Schwartz, Chase, Oppezzo, \& Chin, 2011). If 'understanding the student point-of-view' is achieved by practicing a Pedagogy of Kindness, then students become more engaged and motivated to achieve (Clegg \& Rowland, 2010).

Practicing a Pedagogy of Kindness requires the instructor to develop a deep understanding of each student's learning context (Clegg \& Rowland, 2010) as they develop an understanding of their students' learning pathways. Large class enrolment (i.e., Cash, Letargo, Graether, \& Jacobs, 2017) can immediately come to the forefront of reasons for why these student-centered approaches are not implementable. However, the foundational elements of a positive instructor-student relationship, including kindness, respect, and empathy (Khan \& Armstrong, 2019), are class-size independent and often do not require additional resources (e.g., Gorny-Wegrzyn \& Perry, 2021). Conveying these qualities to a large group is perceived as challenging, when in fact the large group can facilitate community building because a Pedagogy of Kindness encourages students to share with each other by modelling the skills of active listening and cooperation (Magnet, Mason, \& Trevenen, 2014).

In BIOL*1070 the constructivist framework, layered with adult learning theory principles and a Pedagogy of Kindness, ensured learning activities were relevant, scaffolded, and students continued to be active participants in the achievement of their learning goals despite large class size. Course-level LOs, and lecture- and seminar- specific LOs were retained to maintain alignment of assessment, instructional strategies, and learning activities. This alignment promoted self-directed learning, longevity of learning, and use of strategies that promote critical thinking, long-term retention, and applicability of knowledge and skills.

\subsection{A Universal Design for Learning Approach to Remote Learning: Ensuring Access}

We used Universal Design for Learning (CAST, 2018) as a framework to improve inclusive access and support student mental health. Especially relevant and magnified in a remote online learning environment are the differences in the ways that students engage with course material, perceive and comprehend information, and motivate themselves to learn. To address these differences, a large part of the UDL framework emphasizes finding multiple ways to provide materials to students: multiple ways of representing information, engaging students, and demonstrating knowledge. For example, to recognize that students differ in the way that they perceive and comprehend information, we redesigned the course Learning Management System (LMS) and provided information in multiple formats (text, audio, and visual). To recognize that students differ in the way that they engage with course material and their motivation to learn, we incorporated various motivational strategies such as clear goals and expectations, opportunities for collaboration, and attempts at providing a sense of community in various ways. Attempts at community-building included utilizing upper-year undergraduate student volunteers to assist graduate student teaching assistants and interact with students in synchronous seminars, welcome videos from the instructional team, the opportunity for students to participate in a citizen science project (Squirrel Life), and a 'Community' discussion board where students were invited to create posts about interesting and fun activities they did outside of the course. To address the differing ways that students navigate the learning environment and express their knowledge, we incorporated an organized and intuitive flow to the LMS material and used multiple media to communicate with students (e.g., live synchronous discussions, asynchronous videos, announcements and notifications within the LMS, emails, and discussion board posts).

Assisting students with goal setting and time management also became a focus, where Intelligent Agent personalized messaging was created to alert and remind students of upcoming deadlines if they had not yet submitted a course assessment or completed a task. Due to the nature of circumstances created by the COVID-19 pandemic, these personalized messages were an important opportunity to check in with students and provide useful mental health and learning resources, as the first year of postsecondary education is an important time to provide students with strategies to promote mental health and student success (Wyatt et al., 2017). 
To help students maintain their studies while facing a broad range of challenges, deadlines were extended on major assignments, exams were all 'take home' where students had three days to complete a timed series of online questions, each student received triple time for any timed assessments, and the lowest grade of any one type of assessment was dropped in the final calculation. No assessment was weighted higher than $20 \%$ of the final course grade, and all requests for accommodation or customization were granted. With 537 enrolled students, only $1.7 \%$ received a failing grade.

\section{Designing the Learning Environment to Support Students and Encourage Engagement: Putting Theory into Practice}

The transition from secondary to first-year undergraduate education involves a steep learning curve (Lawrence, 2001; Pargetter, 2000; Perry \& Allard, 2003; Yorke, 2000) that was intensified by the COVID-19 pandemic by exacerbating pre-existing challenges and creating new ones (Baldock, Fernandez, Franco, Provencher, \& McCoy, 2021; Kyne \& Thompson, 2020). At the heart of the challenge of the transition to first-year university is either the loss of (Scanlon, Rowling, \& Weber, 2007) or unstable (Páramo Fernández, Araújo, \& Tinajero, 2017) student personal identity. This disruption in identity can be re-stabilized within a supportive community of peers. With the reduction of non-curricular programs of support offered by institutions, the role of the instructor changed dramatically with the pandemic (e.g., Thomsen et al., 2021). We were not only there to teach, but we were also there to support the whole student in community and peer group building. We realised the importance of in-person learning in helping students remember upcoming deadlines, understand assessment expectations, and sharing tricks to navigating a dense institutional bureaucracy. We realised our critical role in facilitating social engagement, communicating the shared student experiences, and connecting them to one another. Thus, reflecting on the rapid pivot to virtual course delivery in March 2020 in preparation for virtual course delivery commencing in September 2020 (Fall 2020 semester), we considered challenges (since described by Baldock et al. (2021), and Kyne and Thompson (2020)) in the reconstruction of the learning environment. This prepared us to support students academically and personally through various strategies (outlined in subsections 3.1-3.8 and within Table 1) while using the described theoretical framework (section 2) to help us make purposeful decisions.

\subsection{Welcoming Students to the Course: Building An Early Sense of Community}

Having access to an in-person peer community was impossible during the pandemic. Recognizing the importance of ensuring that students felt a sense of community and had the support that they needed (Wyatt et al., 2017), we began building our first-year undergraduate community before the semester began. A week before their first classes, we sent a welcome email to students registered in the course that contained an overview and important information about how the course would be delivered, a draft copy of the course outline, and videos to help students familiarize themselves with the university's LMS and the course LMS, and general tips and tricks about the university (how to download free software, etc.). We arranged early access to the course LMS so that students were able to explore it and become comfortable in navigating it, and we also scheduled an informal open class hour during the orientation week so that students could test out their Zoom access, meet us, and ask questions.

\subsection{Supporting Student Mental Health and Well-Being: Ensuring Students Know They Are Fully Supported}

Effective learning depends on several factors, and quality teaching is just one component of a positive learning environment. A significant factor of learning and motivation is the student - in their self-esteem, well-being, and mental health. Since remote/virtual learning during a pandemic lock down is isolating, students needed to know that they were supported in achieving their academic and personal goals and we did this in several ways (Table 1). Collins (2003) outlines the ways in which students can be supported - by "giving them a hand". Each finger on the hand represents a contribution to a student's self-esteem and well-being: Acknowledgement, Recognition, Application, Achievement, and Matching (Collins, 2003). From the time that students received their welcome email, they are acknowledged as being part of a shared experience and reminded that their individual voice is valued. For every synchronous class held using Zoom, students 'entered the room' to a welcome slide that included a warm greeting from the instructors depicted in cartoon form, group colouring page or puzzle that students could work on collaboratively while they waited for the class to begin, any class-specific announcements, and the details of a song that was being played during these few minutes (Figure 1). The Zoom access for synchronous classes was opened 10-minutes before the scheduled class time to allow students to settle in and prepare for learning, sort out any technological problems prior to class starting, and participate in the optional fun pre-class activities. Simple techniques to support this welcoming culture in a virtual space included allowing students to annotate our shared screens so that they could ask a question or circle a word that they found unclear. Large blank margins were placed on either side of shared content to allow any student to make notes, draw a cartoon, or share a response. Other students who had a similar reaction to 
something, but did not share, could then be reminded of the large community of students they are part of, learning together, and feeling and experiencing similar things. The chat function in Zoom was disabled intentionally and all chatting was diverted to a chat page within the course LMS so that a chat history was saved, and students could choose not to be distracted by Zoom chats. The course is co-instructed, so when one instructor was not actively speaking, they were monitoring the chat, answering questions, and stimulating questions by reacting to what the other instructor was saying. For example: if the speaking instructor is talking about an interesting case related to a concept, then the chat monitor might simply write: "That's so cool!" in the chat to encourage interaction with those students who have chosen to participate in the chat feed. Enhanced contributions might be pasting a link, or attaching an image, though this might also be distracting. We used the 'That's so cool!' approach most frequently because it was quick, easy, and most likely to result in short replies of agreement. In addition, the teaching team made a concerted effort to learn the names of many of the students during teaching interactions, using them when they appeared on the shared screen annotations, and during virtual student hours, to help students feel welcomed, acknowledged, and valued.
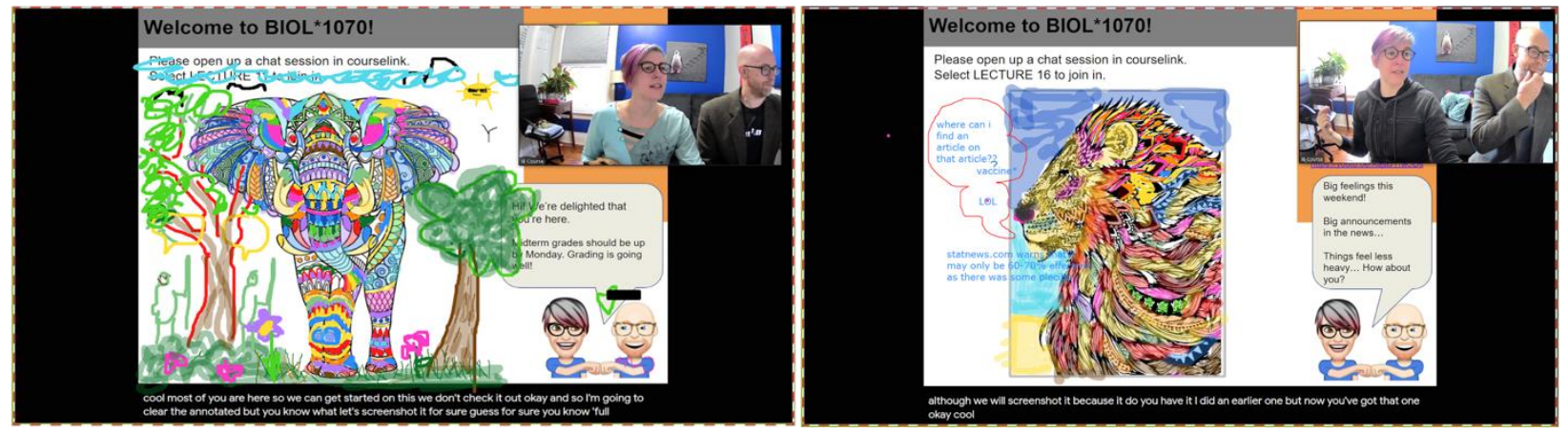

Figure 1. Example of Acknowledgement (Collins, 2003): Create a welcoming environment in a synchronous online class. Music details were in the orange box under the instructor videos. Students watching can see the orange box.

Instructor video feed is placed over the box to support better engagement for those students watching this asynchronously

\subsection{Digitizing Physical Learning Spaces for First Year Students: Providing Virtual Field Experiences}

Field excursions can be life changing for learners. During in-person offerings, our course provided a field excursion to a campus-owned urban forest where students learned to identify plant and tree species, conducted a small-scale ecological sampling protocol, and analyzed the data collected by all the student groups in the class. This activity was associated with a capstone assignment called the Forest Fragmentation Assignment (FFA). The switch to remote learning eliminated the possibility of visiting this site because even though it was outside, and physical distance could be maintained throughout, our students were not all living in our community; they were distributed around the world. Recognizing the benefits of authentic field experiences, we felt it important for students to 'be' on campus, collecting biological data, and having the experiences that their colleagues in previous semesters had on campus.

We accomplished our goals by digitizing the physical spaces where students were learning when in-person; specifically, we redesigned all the small group labs to either synchronous or asynchronous formats, created a digital version of the urban forest, and developed a new capstone assignment that was scaffolded to all previous labs. Rather than visiting the forest in person, students were able to access the forest digitally using GigaPan high resolution images (Smith, 2010). This made it possible for students to complete group activities with their peers: they identify different species of trees using dichotomous keys (see top image, Figure 2), determine and graph their relative abundances, and complete a capstone assignment called the Effect of Pesticide Project (EPP), an improved-upon version of the former FFA. For the EPP, students virtually collect discrete and continuous data on the effect of pesticides on non-target insects in three (virtual) treatment areas (see bottom image, Figure 2), and then compile and analyze these data, create and caption figures, and write an abstract summarizing the results. The insect specimens $(3 \mathrm{~cm}$ long plastic insects painted with different patterns on their backs to represent various measurable characteristics and meaningful life history information) were placed within the actual forest before the GigaPan images were taken, allowing students to 'encounter' these insects when they entered the digital forest. In a scaffolded group interdisciplinary assignment (IA), an alternate version of the former interdisciplinary project, student groups create infographics that outline the ecological, evolutionary, and physiological effects of pesticides on insects using the data that they collect in the EPP as evidence for their conclusions. The IA, unlike the former interdisciplinary project, is now linked to experimental data that students collect and analyze, and students are required to present these data on pesticides to a general audience 
with an infographic, developing their scientific writing and communication skills.

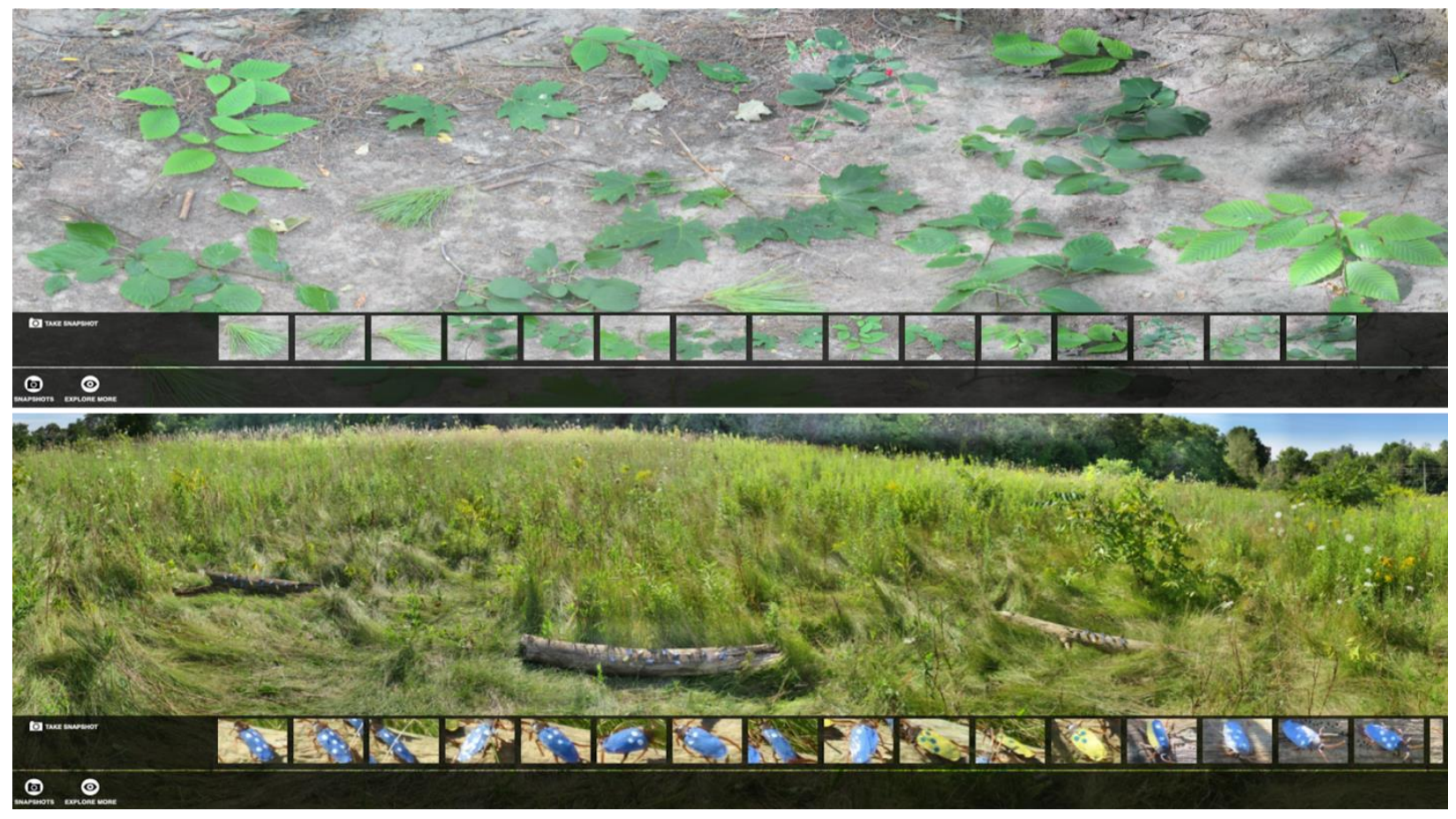

Figure 2. Accessible virtual field experiences using GigaPan high resolution images. Digital forest for identifying tree and shrub species (top image; http://www.gigapan.com/gigapans/22224) and collecting data for the EPP (bottom image; http://www.gigapan.com/gigapans/222249)

\subsection{Practical and Transferable Skills: Developing Skills for Success}

One of the cornerstones of a learner-centred approach to teaching is explicit skills instruction and development and ensuring that students understand the applicability of the skill that they are learning. This approach is also in line with a competency-based curriculum. If a course is focused on the accumulation of knowledge and information without application of this information, then students can find this demotivating and frustrating (Knowles, 1977; Merriam, 2001). Practical skill development in data collection, analysis, and visualisation was enhanced within the virtual course offering of $\mathrm{BIOL}^{*} 1070$, as was scientific writing skill development. Video tutorials and scaffolded assignments were created to introduce students to data management software and scientific writing in a way that reduced the assessment risk of each evaluated task. The use of the software and aspects of scientific writing were distributed throughout the seminars to give students the opportunity to practice using the software and scientific writing in discrete units (i.e., figure captions). Students received valuable constructive feedback on their proficiency and use of the data management software and their scientific writing skills so that they could further improve their skills to illustrate proficiency in the summative capstone EPP assignment and associated IA.

\subsection{The Squirrel Life Project: Providing an Experiential Learning Experience through Citizen Science}

An important component of the student experience is having the opportunity to participate in experiential learning through clubs, volunteering, and research activities (Thiry, Laursen, \& Hunter, 2011), but the COVID-19 pandemic brought an abrupt end to these opportunities, further isolating students. We realized that undergraduate students at the University of Guelph were struggling with the loss of these activities, and more specifically, the loss of what comes with them: building community and authentic connections with like-minded people, participating in activities to gain relevant experience for future career goals and personal development, and the opportunity to participate in extracurricular experiences (Buckley \& Lee, 2021; Finnerty, Marshal, Imbault, \& Trainor, 2021). During a pandemic these outcomes were even more important than before, and after many conversations with students, it became evident that they needed these experiences brought to them, irrespective of where they were geographically. Squirrel Life was developed to achieve our goal of supporting students more holistically, so we incorporated it into BIOL*1070 as an optional bonus project and pilot of the large-scale project. Citizen science is an innovative and powerful tool for providing undergraduate students with authentic research experiences (Mitchell et al., 2017; Oberhauser \& LeBuhn, 2012), in addition to mental and physical health benefits (Domhnaill, Lyons, \& Nolan, 2020). Such citizen science 
projects teach both discipline-specific and transferable skills and knowledge (Kobori et al., 2016; Phillips, Ballard, Lewenstein, \& Bonney, 2019; Phillips, Porticella, Constas, \& Bonney, 2018) and provide an accessible, inclusive, and equitable way to accommodate students that are located all over the world with varying levels of access to the outdoors and other resources. BIOL*1070 students participated in Squirrel Life from North America, South America, Europe, Africa, and Asia.

To participate in Squirrel Life, students went on five 30-minute walks (or other accessible options) over the course of the semester, to count how many squirrels they saw and record observations about squirrel behaviour and other relevant environmental data. Students observed different species of squirrels, and those who could not find squirrels observed alternate species (e.g., feral cats, various species of birds). Squirrel Life allowed the teaching team to deliver an accessible field experience in ecology to all students, irrespective of their locations, while also supporting their personal and professional development, health, and well-being within and outside of class time. Students reported that 1) they felt encouraged to step away from the screen to go (or look) outside, 2) engaging with nature helped them to de-stress, 3) they felt motivated to be more physically active, and 4) it gave them an opportunity to participate in a safe activity with other members in their 'social bubble'. Several themes emerged from student feedback about participating in Squirrel Life including appreciation for an authentic research and field experience, encouragement to take screen breaks to support physical and mental well-being, a sense of community through the opportunity to connect with others working towards a common goal, and a fascination and deeper appreciation for the natural world and all the details of nature.

\subsection{Discussion Boards: Encouraging Collaboration, Learning, and A Greater Sense of Community}

To create a community of learners, the teaching team used discussion boards within the course LMS. These discussion boards allowed students to ask questions outside of the synchronous course time and students were encouraged to answer questions posed by their peers. The instructors monitored the discussion boards to provide feedback on the content-accuracy and the quality of answers and/or reply to a posed question. These discussion boards were also a way for students to synthesize what they were learning and provided a platform for peer-to-peer learning. Students were encouraged to post all questions within these forums instead of emailing the instructors, which increased the efficiency of responses for the instructor and decreased the time a particular student had to wait for an answer to their question. Due to the varied educational backgrounds of the students, students with special skills or knowledge in a certain area became an educational resource and were able to teach their peers. Additionally, we encouraged our team of teaching assistants and undergraduate student volunteers to create short introductory videos about themselves, their research, and hobbies, and post them for all students to view within the Community discussion board. The undergraduate student volunteers also posted short videos about various topics (e.g. Top 5 places to visit at the University of Guelph, or interesting things they were doing in upper-year courses, etc.), or other activities for students to complete like crossword puzzles and word searches that reviewed concepts and terminology related to the course. Students were also encouraged to post pictures of activities outside of class or questions they had about the University of Guelph community. Complementary to this, in the Squirrel Life citizen science project discussion board, participating students were encouraged to share pictures of what they saw during squirrel observations, "Nature Moments" (stories of things they saw or experienced while in nature that fascinated them or that they had questions about) and ask for help with identifying animals they saw.

\subsection{Study Skills Discussions and Resources: Promoting Self-Initiated Learning}

Learning strategy interventions are aimed at improving student performance by enhancing student self-regulated learning skills and metacognition (Donker, de Boer, Kostons, Dignath van Ewijk, \& van der Werf, 2014; Bingham, Coulter, Cottenie, \& Jacobs, in press). To support students in engaging in evidence-informed approaches to studying while fostering a sense of community and belonging, we developed asynchronous study tools using Google Spreadsheets (Figure 3). The Google Spreadsheets application was used throughout the course as a means of learning together on a shared document that could more easily organize the contributions of individuals (in cells) and allow students to revisit those documents throughout the course in a way that other collaborative response platforms do not. These collaborative spreadsheets can be used in breakout rooms or in large groups, both synchronously and asynchronously. All instructions were included on the actual spreadsheet and each sheet had a specific purpose or set of guiding questions. For example, Figure 3 shows a study tool using an artefact (the map) where students are instructed to write True or False statements about concepts that we learned in class as they apply to the information presented in the map. Then, other students can vote on whether they think the statement is true or false by adding a vote tally to the corresponding column. There are also columns for questions and for instructors to comment. This approach allowed students to remain anonymous, write statements without focusing on whether they are either true or false specifically, 
and then receive feedback from their colleagues and instructors by votes or questions. The Google Spreadsheet supported students in feeling as though they were part of a community because they could see each other's work and work collaboratively on the document in a way that a survey tool cannot. Similar designs were used during synchronous breakout sessions with specific questions given at the tops of columns. Instructors were able to monitor all the breakout rooms simultaneously, even in a very large class with many rooms, by reading along with the contributions on the spreadsheet (as long as a specific row/column is assigned to each breakout room).

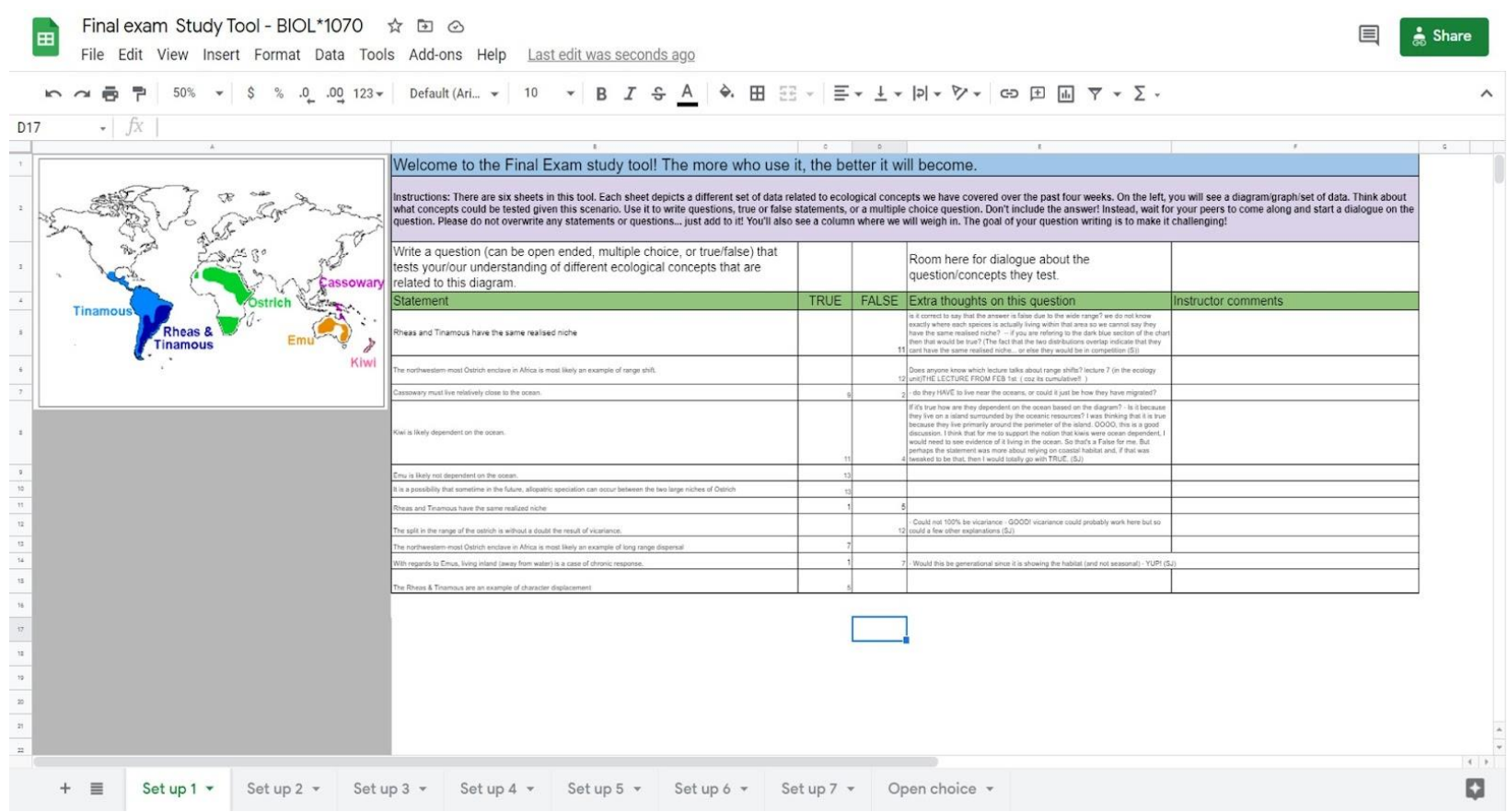

Figure 3. Screenshot of our asynchronous exam study tool using Google Spreadsheets

\subsection{Student Hours: Office Hours to Suit Student Needs}

A critical component in effective teaching is increasing instructor/student contact (Cash et al., 2017; Kuh, O’Donnell, \& Schneider, 2017). Aside from the discussion boards as an avenue for students to ask questions, virtual and one-on-one student hours were offered. For accessibility, the scheduled student hours immediately followed each synchronous class. These student hours were extremely popular, with often over 100 students remaining to ask questions or participate in a discussion for at least 30 minutes. If there were no course-related questions or discussion topics, the instructors took students on a guided tour of something interesting, using tools such as Google Earth, or Wikipedia. Very quickly within the semester, students began sharing their own interesting stories or experiences, with questions to challenge each other. One student (let's call them Leo), who became known for asking 'over the top questions' that made everyone laugh and then think, inspired the "A Leo Question", which simply increased the number of creative questions and reminded students that learning can be fun(ny). 
Table 1. Strategies for mitigating challenges and impacts posed by the need for teaching in a virtual space

\begin{tabular}{|c|c|c|}
\hline Challenge & & Student Impact \\
\hline $\begin{array}{l}\text { Unclear } \\
\text { expectations } \\
\text { course and } \\
\text { delivery }\end{array}$ & $\begin{array}{l}\text { for } \\
\text { its }\end{array}$ & $\begin{array}{l}\text { Students are anxious about what } \\
\text { to expect and worried that they } \\
\text { will not be able to succeed. }\end{array}$ \\
\hline
\end{tabular}

\section{How we addressed challenges and impacts}

'Welcome to the Course' email with detailed information about the course sent to students one week before the official launch of the course; Course welcome video introducing the teaching team and course delivery method; All students given early access to the course Learning Management System (LMS) so that they can explore it before the semester starts.

Lack of schedule or Students miss class, potentially routine impacting course achievement.

Students miss deadlines for assignments, impacting achievement.

Students become frustrated, impacting motivation.

Lack of in-person interaction

Students feel isolated, impacting mental health.

Difficult to assess student progress and understanding of material.

Students feel they are unable to get timely answers to questions or help with assignments.
Comprehensive course schedule posted in the LMS; Offering synchronous lectures mirroring in-person lecture delivery; Offering synchronous seminars at key points during the semester; Weekly reading quizzes to help students stay up-to-date with course readings.

Intelligent agent personal email reminders sent 3 days before a course task or assignment was due.

Intelligent Agent email reminders (as above); Weekly "Getting Ready for Next Week" announcements in the LMS outlining tasks and due dates.

Peer-to-peer interaction and student-instructor interactions through numerous avenues, including synchronous lectures and seminars that include in-class activities requiring participation (annotation, breakout room discussions) and group assignments; Chat during lecture where students can ask questions, react to discussions, and interact with the instructors; Community building activities and discussion board where students were encouraged to make non-course related posts; Undergraduate student volunteers interacted with students in synchronous seminars and in the community discussion board, creating activities, videos, and discussion about life outside the classroom; The Squirrel Life citizen science project encouraged students to go outside to view squirrels with family and friends (while adhering to all COVID-19 social distancing protocols).

Students assigned 'homework' at the end of each lecture, which is taken up at the beginning of the next lecture; Weekly reading quizzes to assess comprehension of readings.

Discussion boards allow students to post questions about lecture material or assignments; Virtual office hours held twice per week; Quick turnaround for emails; Video tutorials provided to scaffold skills building (e.g., data management and use of Excel).

Lecture and seminar activities require students to actively engage through annotation, group discussions, polling, etc.
Lack of student Decreased motivation to learn. engagement 
Lack of active learning

Lack of student support, potentially impacting mental health/wellness or course-related access/activities

Remote assessment structure and delivery
Students lack confidence in content mastery, or overconfidence that they have learned the material using passive approaches.

Personal issues or inadequate internet access impeding access to synchronous lectures or seminars, completion of course tasks and course achievement.

Students feel isolated and not part of the class community. Academic misconduct.

Active learning approach was maintained through in-class activities requiring participation (polling, screen annotation, group discussion in breakout rooms, chat during lecture).

Synchronous lectures were recorded and posted for asynchronous viewing; Lecture slides posted for asynchronous viewing; Flexible accommodations or deadlines if a student is unable to attend synchronous seminar or complete a course task; Students able to drop lowest weekly quiz grade and lowest seminar assignment grade.

See above strategies within 'Lack of in-person interaction'.

Seminar module dedicated to academic integrity, code of conduct, and case studies used to illustrate examples of academic misconduct; Midterms and final exam question banks and randomization of questions chosen; Questions written so that students were unable to Google correct answers during an assessment; allowed collaboration on assignments.

Students unable to receive feedback on assessments or opportunity to address grading concerns.

Use of Dropbox and associated rubrics to allow for timely grading and provision of feedback; Regrade policy allowed students to submit grading concerns; Teaching assistants provided written feedback using a structured and standardized format that was customized for each student.

Students have inadequate internet access or feel pressured for time to complete a midterm or final exam.

Lack of community and feeling of belonging

Students do not feel supported by the course or the institution, potentially leading to attrition.

Exams were delivered over multiple hours or days to ensure access; Triple the amount of time required to complete an assessment was provided to all students to remove the pressure of time constraints and reduce stress surrounding workspace, internet, and/or technology problems.

See strategies above within 'Lack of in-person interaction'; Mental health and other resources provided to students within the LMS and through intelligent agent personal email check-ins.

\section{Evidence of Successful Course Restructuring: Student Feedback}

Though the instructors of this course are all higher education researchers, we felt it unethical to design a study for implementation during this extraordinarily challenging semester for students. Instead, we rely on informal feedback as shared with the instructional team. Online student evaluations of teaching were administered in accordance with institutional policies. Students could choose whether to sign their comments, understanding that signed comments can be used for other purposes. We note just a few of the many positive comments about the various aspects of the course restructuring we implemented in Fall 2020. Despite the challenges of transition to a fully virtual/remote format, students' responses indicated that the evidence-based course modifications we made were positive and supported their learning and experience:

"This was my favourite course this semester. The assignments were easy to follow, the content was engaging, and the topics were full of useful information. Instead of using the current online situation as an excuse to have lacklustre courses, this team created a course that thrived online!'”

Even though we could not be present in the same physical space as students, the materials we provided were accessible to them in a way that inspired them to be more invested in their own learning and skill development:

"This course was amazing. It was extremely interesting and delivered in an understandable way. The seminar assignments allowed first year students to become proficient in skills that may not have been learned in high 
school such as utilizing Excel or scientific writing, allowing students to become comfortable with these skills instead of leaving them to figure things out on their own."

In a time of world-wide uncertainty, we were able to provide a student-centered learning experience that did not take the joy out of learning, but instead removed unnecessary stress to allow students to experiment with new skills and knowledge in a safe space:

"tutorials during the seminar assignments were extremely thorough and easy to understand, erasing some of the anxiety that comes with the expectations of using a brand new skill."

The pilot of the citizen science project, Squirrel Life, was a resounding success:

"I have directly benefited from the experience in a number of ways, from contributing to my mental health, physical health, attention to detail, and scientific data collection skills."

But perhaps the best form of feedback was the final screenshot of the semester (Figure 4).

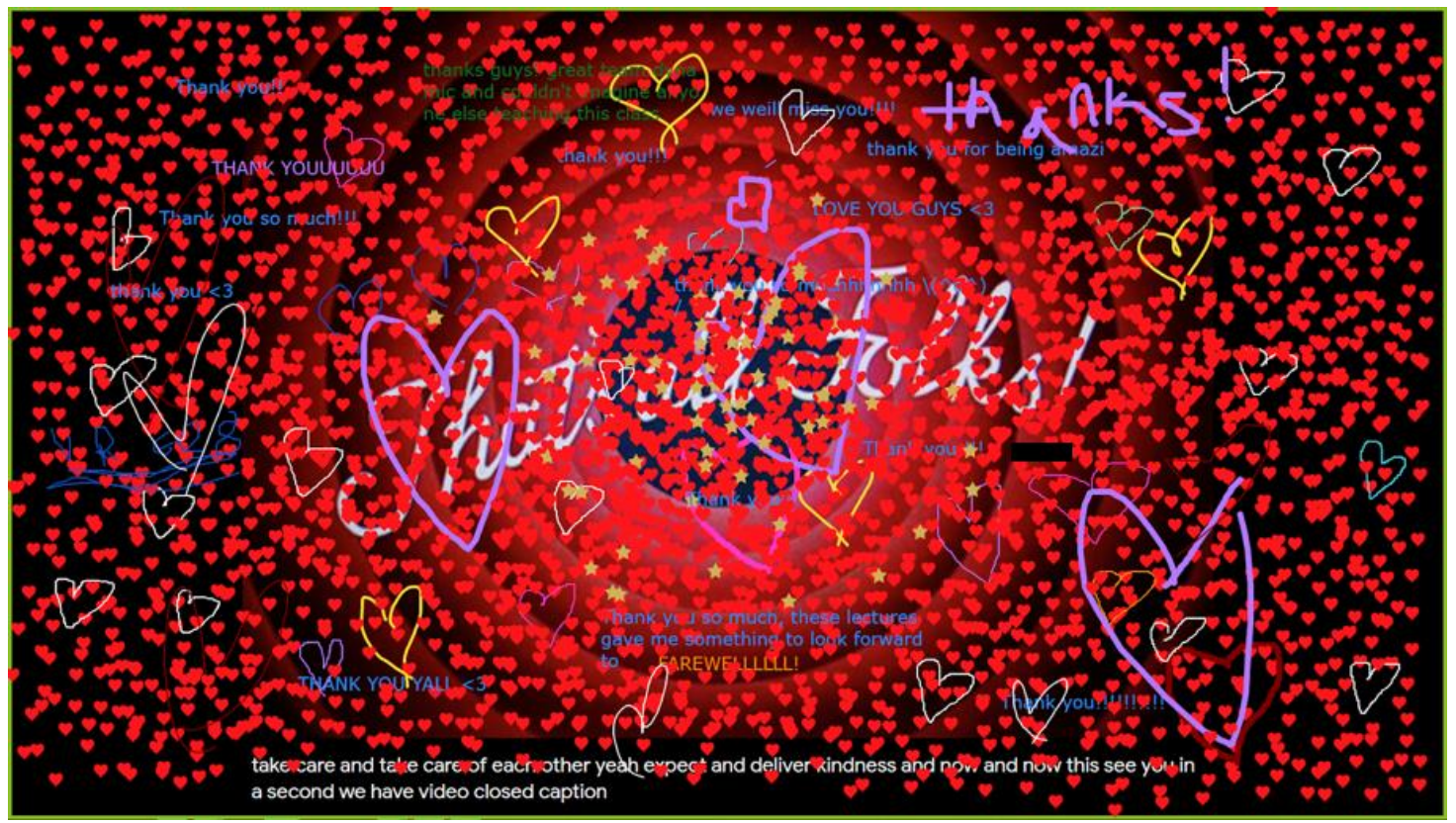

Figure 4. Parting screen as annotated by our students

\section{Moving toward Post-Pandemic Teaching: Lessons Learned and What We will Bring Forward}

The COVID-19 pandemic created unprecedented challenges for teaching and learning, placing enormous amounts of stress on both educators and learners. But instead of concentrating on the negative aspects of the pandemic, we must look at how it has forever transformed teaching and learning. It has provided important opportunities to critically evaluate, modify, and significantly improve postsecondary teaching and course delivery in an expedited fashion. This global event has taught us that we are collectively resilient, and together can face adversity, overcome incredibly challenging situations, and flourish. In the face of the extreme challenges that the COVID-19 pandemic posed, teaching and learning was improved by placing accessibility, equity, inclusion, mental health, and student need at the centre. This was long overdue.

We used existing theories and principles to make evidence-based decisions on course restructuring, and through this process we made the course virtually deliverable, and vastly improved the student learning experience. We intend to retain most of the modifications when we transition back to a (different) in-person instructional method. For example, we will retain the restructuring of the course LMS and will continue to apply a UDL framework. We will retain the scaffolded seminar series with an emphasis on skills development related to data analysis and presentation, and scientific writing. We will continue to use Zoom in in-person classes so that students can continue to engage with our visual material by annotating, drawing, and circling words. Google Spreadsheets will be further improved to increase access to synchronous and asynchronous study materials. Assessment deadlines will be further relaxed, with universally built-in buffer periods. Our digital urban forest will be improved, added to, and will become a tool that students can choose to use for comparisons with the actual forest, or as a means of ensuring equitable access. Most importantly, we will retain our focus on supporting the whole student, including student mental health and wellness, 
which includes the incorporation of the Squirrel Life citizen science project as a core element in the course rather than a bonus activity.

The pandemic has raised important questions to guide further research about the physical spaces needed for teaching and learning. Is there a need for having all students together in one large classroom, or will a combination of synchronous in-person and online instruction become the norm, such that students may choose to enter the physical space or virtual space of the classroom? Must a course be delivered in-person for it to be engaging, stimulating, and motivating? Moving forward, the $\mathrm{BIOL} * 1070$ teaching team will continue to consider these, and many other, questions in the further restructuring of the course to be delivered post-pandemic as we strive to provide a safe and engaging learning environment that gives students the resources that they require to succeed both personally and academically. We are already seeing the impacts that the COVID-19 pandemic is having on mental health and well-being as communities worldwide experience a collective trauma. We must remain vigilant and ensure that we are providing a learning environment conducive to student success.

\section{References}

Baldock, B. L., Fernandez, A. L., Franco, J., Provencher, B. A., \& McCoy, M. R. (2021). Overcoming the challenges of remote instruction: Using mobile technology to promote active learning. Journal of Chemical Education, 98(3), 833-842. https://doi.org/10.1021/acs.jchemed.0c00992

Biggs, J. (1996). Enhancing teaching through constructive alignment. Higher Education, 32, 347-364. https://doi.org/10.1007/BF00138871

Bingham, B., Coulter, C., Cottenie, K., \& Jacobs, S. (2021). The benefits of an online instructional metacognition guide on student performance. Canadian Journal of the Scholarship of Teaching and Learning; in press.

Buckley, P., \& Lee, P. (2021). The impact of extra-curricular activity on the student experience. Active Learning in Higher Education, 22(1), 37-48. https://doi.org/10.1177/1469787418808988

CAST (2018). Universal design for learning guidelines version 2.2 [graphic organizer]. Wakefield, MA: Author.

Cash, C. B., Letargo, J., Graether, S. P., \& Jacobs, S. R. (2017). An analysis of the perceptions and resources of large university classes. CBE—Life Sciences Education, 16(2), ar33. https://doi.org/10.1187/cbe.16-01-0004

Clegg, S., \& Rowland, S. (2010). Kindness in pedagogical practice and academic life. British Journal of Sociology of Education, 31(6), 719-735. https://doi.org/10.1080/01425692.2010.515102

Collins, G. H. (2003). Give self-esteem a hand and improve learning. Journal of Veterinary Medical Education, 30(1), 8-11. https://doi.org/10.3138/jvme.30.1.8

Cuseo, J. (2007). The empirical case against large class size: Adverse effects on the teaching, learning, and retention of first-year students. Journal of Faculty Development, 21(1), 5-21.

Czerniewicz, L., Trotter, H., \& Haupt, G. (2019). Online teaching in response to student protests and campus shutdowns: Academics' perspectives. International Journal of Educational Technology in Higher Education, 16(1), 43. https://doi.org/10.1186/s41239-019-0170-1

de Jong, T. (2010). Cognitive load theory, educational research, and instructional design: Some food for thought. Instructional Science, 38(2), 105-134. https://doi.org/10.1007/s11251-009-9110-0

Dietrich, N., Kentheswaran, K., Ahmadi, A., Teychené, J., Bessière, Y., Alfenore, S., ... Hébrard, G. (2020). Attempts, successes, and failures of distance learning in the time of COVID-19. Journal of Chemical Education, 97(9), 2448-2457. https://doi.org/10.1021/acs.jchemed.0c00717

Domhnaill, C. M., Lyons, S., \& Nolan, A. (2020). The citizens in citizen science: Demographic, socioeconomic, and health characteristics of biodiversity recorders in Ireland. Citizen Science: Theory and Practice, 5(1), 16. https://doi.org/10.5334/cstp.283

Donker, A. S., de Boer, H., Kostons, D., Dignath van Ewijk, C. C., \& van der Werf, M. P. C. (2014). Effectiveness of learning strategy instruction on academic performance: A meta-analysis. Educational Research Review, 11, 1-26. https://doi.org/10.1016/j.edurev.2013.11.002

Finnerty, R., Marshall, S. A., Imbault, C., \& Trainor, L. J. (2021). Extra-curricular activities and well-being: Results from a survey of undergraduate university students during COVID-19 lockdown restrictions. Frontiers in Psychology, 0. https://doi.org/10.3389/fpsyg.2021.647402 
Gazmararian, J., Weingart, R., Campbell, K., Cronin, T., \& Ashta, J. (2021). Impact of COVID-19 pandemic on the mental health of students from 2 semi-rural high schools in Georgia. Journal of School Health, 91(5), 356-369. https://doi.org/10.1111/josh.13007

Gorny-Wegrzyn, E., \& Perry, B. (2021). Inspiring educators and a pedagogy of kindness: A reflective essay. Creative Education, 12(1), 220-230. https://doi.org/10.4236/ce.2021.121017

Hariri, P. (2021). Dr. Fiona Rawle on the pedagogy of kindness. The Medium, 47(19). Retrieved from https://themedium.ca/features/the-pedagogy-of-kindness/

Hativa, N., Barak, R., \& Simhi, E. (2001). Exemplary university teachers: Knowledge and beliefs regarding effective teaching dimensions and strategies. The Journal of Higher Education, 72(6), 699-729. https://doi.org/10.2307/2672900

Hodges, C., Moore, S., Lockee, B., Trust, T., \& Bond, A. (2020, March 27). The difference between emergency remote teaching and online learning. Educause Review. Retrieved from https://er.educause.edu/articles/2020/3/the-difference-between-emergency-remote-teaching-and-online-learning

Husband, B. C., Bettger, W. J., Murrant, C. L., Kirby, K., Wright, P. A., Newmaster, S. G., .. Wolf, P. (2015). Applying a linked-course model to foster inquiry and integration across large first-year courses. Canadian Journal of Higher Education, 45(4), 244-260. https://doi.org/10.47678/cjhe.v45i4.184783

Jacobs, S., Loring, P., \& Gillis, D. (2020). The university remains open for instruction, but closed for most other services. Canadian Science Policy Centre, 1(1), 26-28. Retrieved from https://sciencepolicy.ca/posts/universities-remain-open-for-instruction-but-closed-for-most-other-services/

Kerr, A. (2011). Teaching and learning in large classes at Ontario universities: An exploratory study. Toronto: Higher Education Quality Council of Ontario.

Khan, S., \& Armstrong, A. (2019). Math-a-POLKA: Mathematics as a place of loving kindness and . . Journal of the Canadian Association for Curriculum Studies, 17(1), 1-12. http://orcid.org/0000-0001-9995-9016

Knowles, M. S. (1977). Adult learning processes: Pedagogy and andragogy. Religious Education, 72(2), $202-211$. https://doi.org/10.1080/0034408770720210

Kobori, H., Dickinson, J. L., Washitani, I., Sakurai, R., Amano, T., Komatsu, ... Miller-Rushing, A. J. (2016). Citizen science: A new approach to advance ecology, education, and conservation. Ecological Research, 31(1), 1-19. https://doi.org/10.1007/s11284-015-1314-y

Kolb, D. A. (1984). Experiential learning: Experience as the source of learning and development. Englewood Cliffs, N.J: Prentice-Hall.

Kuh, G., O’Donnell, K., \& Schneider, C. G. (2017). HIPs at Ten. Change: The Magazine of Higher Learning, 49(5), 8-16. https://doi.org/10.1080/00091383.2017.1366805

Kyne, S. H., \& Thompson, C. D. (2020). The COVID cohort: Student transition to university in the face of a global pandemic. Journal of Chemical Education, 97(9), 3381-3385. https://doi.org/10.1021/acs.jchemed.0c00769

Lawrence, J. (2001). Academics and first-year students: Collaborating to access success in an unfamiliar university culture. Widening Participation and Lifelong Learning, 3(3), 4-14.

Magnet, S., Mason, C. L., \& Trevenen, K. (2014). Feminism, pedagogy, and the politics of kindness. Feminist Teacher, 25(1), 1-22. https://doi.org/10.5406/femteacher.25.1.0001

McCombs, B. (2015). Learner-centered online instruction. New Directions for Teaching and Learning, 144, 57-71. https://doi.org/10.1002/tl.20163

Mcintosh, E., \& Barden, M. (2019). The LEAP (Learning Excellence Achievement Pathway) framework: A model for student learning development in higher education. Journal of Learning Development in Higher Education, 14. https://doi.org/10.47408/jldhe.v0i14.466

McLaughlin, J. E., Roth, M. T., Glatt, D. M., Gharkholonarehe, N., Davidson, C. A., Griffin, L. M., ... Mumper, R. J. (2014). The flipped classroom: A course redesign to foster learning and engagement in a health professions school. Academic Medicine, 89(2), 236-243. https://doi.org/10.1097/ACM.0000000000000086

Merriam, S. B. (2001). Andragogy and self-directed learning: Pillars of adult learning theory. New Directions for Adult and Continuing Education, 2001(89), 3-14. https://doi.org/10.1002/ace.3 
Mitchell, N., Triska, M., Liberatore, A., Ashcroft, L., Weatherill, R., \& Longnecker, N. (2017). Benefits and challenges of incorporating citizen science into university education. PLOS ONE, 12(11), e0186285. https://doi.org/10.1371/journal.pone.0186285

Oberhauser, K., \& LeBuhn, G. (2012). Insects and plants: Engaging undergraduates in authentic research through citizen science. Frontiers in Ecology and the Environment, 10(6), 318-320. https://doi.org/10.1890/110274

O'Keeffe, P. (2013). A sense of belonging: Improving student retention. College Student Journal, 47(4), 605-613.

Páramo Fernández, M. F., Araújo, A. M., \& Tinajero, C. (2017). Predictors of students' adjustment during transition to university in Spain. Psicothema, 29.1, 67-72. https://doi.org/10.7334/psicothema2016.40

Pargetter, R. (2000). Transition: From a school perspective. Journal of Institutional Research, 9(1), 14-21.

Perry, C., \& Allard, A. (2003). Making the connections: Transition experiences for first-year education students. Journal of Educational Enquiry, 4(2).

Phillips, T. B., Ballard, H. L., Lewenstein, B. V., \& Bonney, R. (2019). Engagement in science through citizen science: Moving beyond data collection. Science Education, 103(3), 665-690. https://doi.org/10.1002/sce.21501

Phillips, T., Porticella, N., Constas, M., \& Bonney, R. (2018). A framework for articulating and measuring individual learning outcomes from participation in citizen science. Citizen Science: Theory and Practice, 3(2), 3. https://doi.org/10.5334/cstp.126

Prince, M. (2004). Does active learning work? A review of the research. Journal of Engineering Education, 93(3), 223-231. https://doi.org/10.1002/j.2168-9830.2004.tb00809.x

Scanlon, L., Rowling, L., \& Weber, Z. (2007). "You don't have like an identity ... you are just lost in a crowd": Forming a student identity in the first-year transition to university. Journal of Youth Studies, 10(2), 223-241. https://doi.org/10.1080/13676260600983684

Schwartz, D. L., Chase, C. C., Oppezzo, M. A., \& Chin, D. B. (2011). Practicing versus inventing with contrasting cases: The effects of telling first on learning and transfer. Journal of Educational Psychology, 103(4), 759. https://doi.org/10.1037/a0025140

Serbati, A., Aquario, D., Re, L. D., Paccagnella, O., \& Felisatti, E. (2020). Exploring good teaching practices and needs for improvement: Implications for staff development. Journal of Educational, Cultural and Psychological Studies (ECPS Journal), 21, 43-64. https://doi.org/10.7358/ecps-2020-021-serb

Sigal, M., \& Jacobs, S. (2019). Preparing for university: An applied analysis on the efficacy of 4U and university level preparatory STEM courses. The Canadian Journal for the Scholarship of Teaching and Learning, 10(1). https://doi.org/10.5206/cjsotl-rcacea.2019.1.7996

Smith, M. A. (2010). A year in an urban forest: Dairy Bush GigaPan 2009-2010. Proceedings of the Fine International Conference on Gigapixel Imagine for Science, November 11-13 2010.

Thiry, H., Laursen, S. L., \& Hunter, A. B. (2011). What experiences help students become scientists? A comparative study of research and other sources of personal and professional gains for STEM undergraduates. Journal of Higher Education, 82(4), 357-388. https://doi.org/10.1080/00221546.2011.11777209

Thomsen, P. S., Tuiburelevu, L., Keil, M., Leenen-Young, M., Sisifa, S. P., Müller, K., ... Naepi, S. (2021). Practising Pacific pedagogies during New Zealand's level four lockdown: Pacific early career academics and COVID-19. Waikato Journal of Education, 26, 149-161. https://doi.org/10.15663/wje.v26i1.754

United Nations Educational, Scientific and Cultural Organization. (2020). COVID-19 educational disruption and response. Retrieved from https://en.unesco.org/covid19/educationresponse

Wyatt, T. J., Oswalt, S. B., \& Ochoa, Y. (2017). Mental health and academic success of first-year college students. International Journal of Higher Education, 6(3), 178. https://doi.org/10.5430/ijhe.v6n3p178

Yorke, M. (2000). Smoothing the transition into higher education: What can be learned from student non-completion. Journal of Institutional Research, 9, 35-47.

\section{Copyrights}

Copyright for this article is retained by the author(s), with first publication rights granted to the journal.

This is an open-access article distributed under the terms and conditions of the Creative Commons Attribution license (http://creativecommons.org/licenses/by/4.0/). 